\title{
META-ESTÉTICA E ÉTICA FRANCESA DO SENTIDO (DERRIDA, DELEUZE, SERRES, NANCY)
}

Stéphane Huchet ${ }^{*}$

\begin{abstract}
RESUMO “Meta-estética e ética francesa do sentido" é uma análise de alguns conceitos formadores do chamado "pós-estruturalismo" e de certos aspectos de sua seqüência histórica. Através de fontes textuais de pensadores que ocupam um momento significativo da produção filosófica internacional, com Jacques Derrida, Gilles Deleuze, Michel Serres e Jean-Luc Nancy, dos anos sessenta até os noventa, o texto coloca em perspectiva conceitos nevrálgicos e estratégicos ressituados nas suas implicações críticas. A manifestação das convergências ligando os pensamentos desses quatro filósofos permite ressaltar os bastidores especulativos de uma "condição poética do pensamento" (Alain Badiou) delineando os contornos de uma meta-estética do sentido que é ao mesmo tempo uma ética. Essa fusão, bem sintetizada na fórmula de Michel Serres, que diz que "a moral é a física", é determinada pelas elaborações, as experimentações e as conquistas realizadas na filosofia derridiana da desconstrução, na filosofia deleuziana do conceito, na filosofia serresiana da física e na filosofia nancyana da arealidade. Os processos em jogo nesses sistemas tentam descobrir nos estratos aporéticos do pensamento as chances de induzir uma cosmologia paradoxal e inaudita.
\end{abstract}

Palavras-chave Meta-estética, desconstrução, conceito, geo-ética, arealidade, evento

* Professor da Escola de Arquitetura da Universidade Federal de Minas Gerais. Artigo recebido em abril de 2004 e aprovado em julho de 2004. (s.huchet@metalink.com.br)

KRITERION, Belo Horizonte, $n^{0}$ 110, Dez/2004, p. 321-349 
ABSTRACT "Meta-aesthetic and French ethics of sense" analyses some concepts which shape the so-called "post-structuralism" and some aspects of its historical sequencing. Through textual sources of thinkers which determine a very significant moment of the international philosophical production, such as Jacques Derrida, Gilles Deleuze, Michel Serres and Jean-Luc Nancy, it leads from the sixties to the nineties, the text puts into perspective some crucial and strategic concepts replaced in its critical implications. The manifestation of the convergences that link the ideas of these four philosophers enables to enforce the speculative background of what Alain Badiou calls the "poetical condition of thinking", delimiting the outlines of a meta-aesthetic of sense which, at the same time, is an ethics. This coalescing, so well summarized by Michel Serres' formula — "morals is physics" — is determined by the elaborations, the experimentations and the conquests carried out by the Derridian philosophy of deconstruction, the Deleuzian philosophy of concept, the Serresian philosophy of physics and the Nancyan philosophy of areality. The at stake betted in these "systems" try to discover in the aporetical stratum of thinking the chances to induce a paradoxical and unheard cosmology.

Key-words Meta-aesthetics, Desconstruction, Concept, Geo-ethics, Areality, Event

Durante muito tempo, a filosofia francesa foi (e teve fama de ser) uma filosofia da consciência. Essa característica tem sua origem na associação do gesto racionalista fundador da subjetividade com o nome de seu criador, Descartes. Sabemos que o século XX conheceu inúmeras ampliações dessa origem na rememoração husserliana das Meditações cartesianas e na sequiência dos pensamentos fenomenológicos de Emmanuel Lévinas, Jean-Paul Sartre e Maurice Merleau-Ponty. Tratava-se já de promover as linhas de constituição intersticiais de uma consciência outra: as vozes do ante-racional, do ante-predicativo e daquilo que Husserl chamou de Ur-theoretisch. O possante "Avantpropos" da Fenomenologia da percepção (1945) formulava os desafios de uma fenomenologia ampliada que iria caracterizar a produção conceitual de não apenas Merleau-Ponty, mas também de Sartre (L'être et le néant, 1943) e de Emmanuel Lévinas, nas notáveis análises de En découvrant l'existence avec Husserl et Heidegger, estudos que cobrem três décadas, entre 1932 e 1959.

Um grande trabalho consistiria em procurar as vias pelas quais a 
fenomenologia francesa de meados do século XX pode ter preparado e liberado o terreno para que jovens filósofos, que constituirão a chamada geração pósestruturalista dos anos sessenta, prolongassem, ampliassem e deslocassem a exploração das filosofias do sentido, do corpo e dos fenômenos indissociavelmente ontológico-estéticos para, ao mesmo tempo, esvaziar-lhes os rastros de filosofia da consciência (ou, como dirá Jacques Derrida, da "presença") e estabelecer os termos complexos de uma forma de geologia conceitual. Através de uma forma de radiografia analítica de alguns conceitos forjados desde o fim dos anos sessenta até os anos noventa, esse percurso drenará uma conceituação que, apesar da enormidade do material bibliográfico que a caracteriza, não deixa de representar ainda um mundo especulativo pouco investigado.

\section{A desconstrução segundo Jacques Derrida}

Revezando de certa forma o cartesianismo universitário das filosofias do sujeito e do conhecimento enquanto consciência, para abri-las e superá-las, a fenomenologia é uma forma de destino da filosofia francesa do século XX. Tal é o legado: o husserlianismo se caracteriza pela reivindicação ao mesmo tempo da herança kantiana da teoria do conhecimento fundado em razão e da herança cartesiana do fundamento de todo pensamento na experiência e na tese do ego cogito. A importância da fenomenologia husserliana reside no gesto de fundar os conhecimentos, as produções lógicas e os atos de percepção na intuição interna de um ego transcendental, que é consciência de si e consciência constituidora de toda realidade visada. Pólo lógico de uma teoria geral dos conhecimentos, pólo ontológico da fundação do mundo no movimento intencional da consciência, pólo egológico da exploração da consciência de si como fonte absoluta, tal é a cartografia da fenomenologia.

Nesse sentido, a fenomenologia foi uma filosofia das formas de constituição transcendental do mundo. A força da presença histórica e intelectual da fenomenologia, na filosofia francesa dos anos quarenta, cinqüenta e sessenta, permite entender a ex-plicação que o jovem meteoro, Jacques Derrida, desenvolveu nos anos sessenta e setenta, com o legado fenomenológico. Derrida sugere o quanto a fenomenologia foi um gesto neo-cartesiano de fundação transcendental e eidética do ser-ao-mundo, de busca da boa formação da presença mútua do mundo e do sujeito, quando escreve que

os conceitos pelos quais traduziu-se e determinou-se eidos ou morphè remetem ao tema da presença em geral. [...] Que o pensamento metafísico - e por conseqüência a fenomenologia - seja pensamento do ser enquanto forma, que o pensamento se pense nela enquanto pensamento da forma e da formalidade da forma, não há nisso 
senão apenas o necessário e perceber-se-ia disso um último signo no fato de Husserl determinar o presente vivo (lebendige Gegenwart) como a "forma" última, universal, absoluta da experiência transcendental em geral. ${ }^{1}$

Estar presente ao mundo e o mundo estar presente na e aderir à minha consciência, tais são as vias de uma fundação subjetiva-mundana do ser. Pensar a plasticidade dessa fundação nunca deixou de ser a tarefa da fenomenologia francesa. "mise en regard" e "concept de forme"2 organizam o domínio fenomenológico de uma recoleção de alguns requisitos óptico-geométricos vinculados à e pela metafísica. Uma passagem exigida pela recente epistemologia francesa da $\operatorname{arte}^{3}$ nos mostraria como, na articulação do paradigma cognitivo da perspectiva monocular com a fundação da objetividade do mundo pelo ego cartesiano, a ordenação em olhar - "mise en regard" - e o conceito de forma encontram uma cena e um aparato teóricos antecipando a investigação e a conceituação pós-cartesiana e fenomenológica da presença mútua do mundo e do sujeito na visão eidética deste e na doação daquele.

$\mathrm{O}$ vocabulário derridiano abriu caminhos ousados na filosofia francesa recente. A análise desconstrutiva da fenomenologia foi colocada sob o signo daquilo que chamaremos muito metafisicamente de fatum dos sentidos. La voix et le phénomène (1967), "Le puits et la pyramide", "La mythologie blanche" (ensaios de 1968 que viraram capítulos de Marges de la philosophie, 1972), "La parole soufflée" (capítulo de L'écriture et la différence, 1967), La dissémination (1972) etc., e outros tantos títulos que remetem à linguagem metafórica essencial da metafísica desde Platão (a luz, a sombra etc., a filosofia como foto-logia). ${ }^{4}$ Essa ex-plicação com os filosofemas da metafísica, que se caracterizariam por um vocabulário veiculando implicitamente um leque de noções metafóricas, como Nietzsche disse no Livro do Filósofo, sublinha o destino de uma filosofia que nunca pôde escapar de seus fundamentos no ser sensível. Foi a ex-plicação com a metafísica, enquanto "metafórica" do especulativo, que abriu os caminhos da colocação da questão do ser sob o signo da linguagem e do fenômeno estético. A tradição literária francesa sempre suscitou a ressonância especulativa que a filosofia criou para ela. Bastaria lembrar Georges Bataille e Pierre Klossowski a respeito de Sade, de Lascaux, de Manet; Sartre a respeito de Mallarmé, Saint Genet e outras tantas Situações

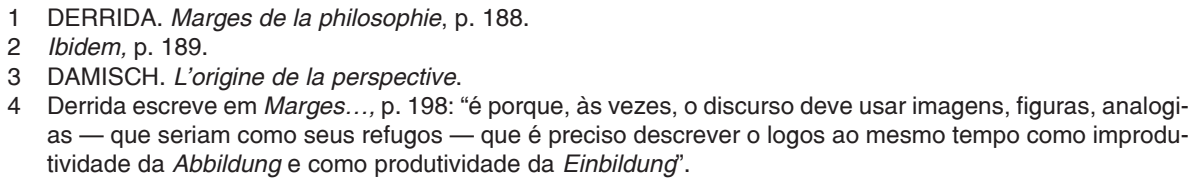


literárias; Maurice Blanchot escritor e filósofo do Espaço literário e de Le livre à venir (o romantismo alemão, Rilke, Van Gogh, Kafka etc.), Gilles Deleuze, Félix Guattari com Kafka, Wörringer e o Barroco de A dobra; Derrida com La vérité en peinture ou Ulysse gramophone (Joyce); Philippe LacoueLabarthe com Hölderlin ou Paul Celan em La Poésie comme expérience, e junto com Jean-Luc Nancy, o fantástico mapeamento do projeto crítico do Romantismo alemão etc. Muito sintomático é o fato de tantos livros de filosofia acabarem ou suspenderem sua marcha numa verdadeira ontologia da arte. Derrida, por exemplo, produziu em 1991 uma exposição a partir de desenhos escolhidos no acervo do museu do Louvre (catálogo Mémoires d'aveugle, l'autoportrait et autres ruines). Dentro de uma epistemologia, de uma psicanálise e de uma antropologia das imagens ocidentais da cegueira, o textocatálogo que o acompanhava era uma grande rememoração da tradição francesa, merleau-pontyana e lacaniana, da visão e do olhar. Não há filósofo francês que não afirme que o fenômeno estético é um momento privilegiado da estrutura, da estatura e do estatuto do Ser.

$\mathrm{Na}$ síntese da filosofia francesa recente proposta por Eric Alliez, por exemplo, a problemática estética é prevalecente. A tese de uma "impossibilidade da fenomenologia" fecha-se precisamente pelo questionamento da arte. A recepção e a reelaboração da fenomenologia pelos filósofos franceses tornoua sempre mais uma fenomenologia da arte. Poder-se-ia dizer que, da carne e da filosofia do ser pictórico (Cézanne; Klee) por Merleau-Ponty (de Doute et sens de Cézanne a $O$ olho e o espírito) até a interpretação derridiana da metafísica como "metafórica" generalizada, a filosofia investiu de maneira possante e inaudita o continente da imagem e da metáfora e sua autoapresentação como ficção generalizada. É possível dizer que a literatura ofereceu sempre aos pensadores franceses o lugar de manifestação de uma ficção ontológica que, enquanto modalidade privilegiada do ser ao mundo, é um ser-aos-fenômenos pelo corpo. Veremos como o corpo é um conceito fundamental da recente filosofia francesa.

\section{A deriva da origem e o espaçamento do sentido}

O conceito derridiano de metáfora quer afastar a filosofia de qualquer lembrança de uma verdade transcendente, plena e fundadora. A força de sua argumentação, sobretudo no fim dos anos sessenta, reside no fato de mostrar que a "diferença" marcada que trabalha o pensamento filosófico lhe é imanente, e de achatar a rede dual da transcendência metafísica no processo de espaçamento radical do ser. $\mathrm{O}$ ser enceta-se e desdobra-se sempre-jà à medida que 
produz as manifestações pretensamente imediatas e plenas de sua atestação. Como o lembram os primeiros passos da desconstrução derridiana da metafísica, toda présentation é "sempre-jà" modificada.

A temática da Força e da Forma entra nesse contexto. A metáfora, diz Derrida, está autorizada pelo inicial deslocamento analógico do ser sobre os entes. É aquilo pelo qual a filosofia enceta e abre a história. Para faire le sens (fazer (o) sentido), a Força cede perante a Forma ou Eidos, a essência ideal e invariável à qual os objetos são conformes e que propicia a perspectiva nocional. O primeiro ensaio ("Force et signification") de L'écriture et la différence fechase precisamente com a afirmação neo-nietzscheana da abertura da história pela diferença entre Apolo (a Forma) e Dionísio (a Força). Apolo e Dionísio abrem, dividem-e articulam-se mutuamente enquanto diferença da Forma (da Gestalt) e da Força (da energia); energeia vs ergon, tal é a abertura (do sentido) da história, porque o fenômeno de formatação e de consolidação nocional é semprejà condicionado por e condicionador de um fluxo vital que atravessa-o inelutavelmente - o que Nietzsche formulou como sendo a metáfora subjacente a seu congelamento pelo conceito e o que Jean-François Lyotard chamará, na introdução de Discours, figure, o "seismo que faz o sentido". Por essa razão, as estratégias de estabelecimento do sentido na metafísica nunca escaparam à vontade de fortalecer sua própria organização arquitetural, a força sendo submetida à vontade de canalizar a significação. Metáfora(s)? Talvez, mas tornam mesmo a essência uma probabilidade. Numa sentença emblemática de seu gesto filosófico, Derrida afirma:

Não é preciso nos surpreendermos se a generalidade (a origem em geral) vira cúmplice da metaforicidade e se é do tropo que aprendemos o que é o sentido próprio e aquilo que se dá enquanto sentido próprio. ${ }^{6}$

Subverter a dominação da energia pelo ser, pelo eidos e por uma significação onde predominaria a verdade prévia do significado é a tarefa da desconstrução. O gesto derridiano consiste numa des-locação e num auto-deslocamento do sentido ou, em outros termos, do querer-dizer inerente à autoapropriação e à auto-proferição do ser. É assim que, ao analisar o pensamento da "fonte" ("source") por Paul Valéry, Derrida encontra a premonição da diferença. A propósito da imagem escolhida pelo poeta, a da passagem da água no tronco e nos ramos da árvore - modelo arborescente que Gilles Deleuze critica depois em Mille Plateaux —, Derrida escreve:

5 LYOTARD, Jean-François. Discours, figure, p. 15.

6 DERRIDA, Jacques, Marges..., p. 333. 
Momento em que a árvore erguida, portanto atravessada, afastada dela mesma no seu dentro, deixa-se cortar da fonte simples. [...] é deixar-se multiplicar ou dividir pela diferença do outro: cessar de ser (um) eu. Logro da fonte [...] tornar-se de novo presente a si, voltar a si, reencontrar, com a pura transparência da água, a miragem sempre eficiente daquele ponto de surgimento, daquele instante do brotar, essa fonte ou esse poço chamado de Verdade, que sempre fala para dizer Eu. ${ }^{7}$

Derrida vai mostrar como o conceito de origem, tão fundamental na fenomenologia, quando colocado sob o signo da fonte, não é mais "coincidência da presença e do evento inicial" , para "descobrir ('déceler') na fonte a brecha ('l'écart') de uma diferença absoluta". Crítica da consciência, crítica da autoreconquista da origem na pretensão da transparência e da auto-presença na proferição vocal ("a fonte sendo alterada [...] o tempo se abre enquanto aquele atraso da origem sobre ela mesma"9) colocam em jogo a filosofia na sua integralidade. A filosofia é somente um timbre e um estilo, diferença fundamental do sentido na sua proferição:

O espontâneo não pode surgir enquanto inicialidade pura do evento senão sob a condição de não apresentar-se ele mesmo.[...] Requeremos aqui uma lógica paradoxal do evento enquanto fonte que não pode apresentar-se, ocorrer-se. ${ }^{10}$

Por essa razão, a palavra de ordem inicial das Marges de la philosophie é "timpanizar - a filosofia."11 "Luxar o corpo da filosofia" significa usar da metaforicidade que lhe é inerente para sustentar, pela economia da heterogeneidade, uma subtração do pensamento às palavras de ordem de dominação do sentido pelo discurso transcendental do ser. Tratar-se-ia de defrontar-se com a resistência da filosofia mesma:

Qual é a resistência específica do discurso filosófico à desconstrução? É o domínio infinito que a instância do ser (e do) próprio parece assegurar-lhe; permitindo-lhe interiorizar qualquer limite como ente e como sendo propriamente seu. ${ }^{12}$

\section{Os ensaios de Marges}

[...] interrogam a filosofia além de seu querer-dizer, não a tratam apenas como discurso: mas como um texto determinado, inscrito num texto geral, fechado na representação

7 Ibidem, p. 329.

8 Ibidem, p. 345.

$9 \mathrm{Idem}$.

10 Ibidem, p. 353.

11 -lbidem, p. I.

12 Ibidem, p. XIV. 
de sua própria margem [...] Onde passou o corpo do texto quando a margem não é mais uma virgindade secundária senão uma reserva inesgotável, a atividade estereográfica de uma audição completamente outra? ${ }^{13}$

Derrida sugere o exercício de uma armadilha no fato de a dialética e a metáfora, indissociáveis, terem permitido "chamar de sentido aquilo que deveria ser estrangeiro aos sentidos."14

O recolhimento último dos gestos metafísicos na desconstrução derridiana teria vindo precipitar o fim do regime hierárquico do pensamento filosófico e entregar a invenção conceitual a migrações num solo achatado percorrido por intervalos e tropos linguagético-retóricos. Habermas situou muito bem isso quando falou da desconstrução derridiana como de um privilégio dado à retórica para alcançar o estilo lingüístico do ser ${ }^{15}$, essa essência linguagética, acabando por se transformar numa determinação estética do mundo pela linguagem. Ao apontar a metáfora, encontramos algo que, numa vertente própria, Gilles Deleuze formulará como característica do pensamento: de somente poder ser o que é - expressão — graças a suas linhas de fuga linguagéticas.

\section{Rumo a uma meta-estética: Gilles Deleuze (e Félix Guattari)}

O processo de mapeamento dos gestos filosóficos franceses recentes por Eric Alliez toma como núcleo a tese de uma "impossibilidade da fenomenologia". Permite chegar ao domínio central da nossa análise: o materialismo da filosofia do acontecimento. Este encontra uma área de inteligência dentro da crítica deleuze-guattariana da fenomenologia. Sua rapsódia distribui-se entre Mille Plateaux (1980) e a formulação sintética de Qu'est-ce que la philosophie? (1991). O que Deleuze e Guattari reprovam é o fato de a fenomenologia ter coberto o lanço na desnaturação dos conceitos pelas funções de tipo lógico-científico que sempre remetem a uma referência, a um estado de coisas dentro de uma temporalidade marcada. Tal é o esquema saliente: a própria fenomenologia, através do exercício noético-noemático que, por ser "função do vivido" torna tudo "significante", teria, inclusive, pecado porque teria dado ao gesto filosófico de cunho analítico um aspecto de sua motivação duvidosa que consiste em submeter a análise e a avaliação das verdades proposicionais a uma função verificatória de tipo lógico-científico. Para a fenomenologia,

15 In: HABERMAS. Le discours philosophique de la modernité. 
o conceito como significação é tudo isso ao mesmo tempo: imanência do vivido ao sujeito, ato de transcendência do sujeito em relação às variações do vivido, totalização do vivido ou função desses atos. Dir-se-ia que os conceitos filosóficos não se salvam senão ao aceitar se tornarem funções especiais, desnaturando a imanência de que eles precisam. ${ }^{16}$

Assim, segundo Deleuze-Guattari, a fenomenologia husserliana é

uma lógica transcendental [...] que desposa a terra e tudo o que ela leva, e que serve de solo primordial à lógica formal e às ciências regionais derivadas. Será portanto preciso que, no seio da imanência do vivido a um sujeito, se descubram atos de transcendência desse sujeito, capazes de constituírem as [...] referências conceituais ${ }^{17}$.

Como o lembram Deleuze e Guattari, a lógica que impera aqui é a da "recognição" do verdadeiro dentro das proposições informativas, isto é, um pragmatismo pobre, a lógica da "função do vivido" ou da proposição de opinião sendo sempre uma lógica de recognição. ${ }^{18}$ A fenomenologia, ao invocar o vivido primordial do sujeito, cria e reforça as proto-opiniões, ou investe os resultados da formação da opinião (Urdoxa natural) como tantas instâncias de constituição de clichês e novas afeições prometidas.

Não há maior pecado do que o fato de desnaturar o conceito pela referenciação inerente ao exercício das correlações noético-noemáticas. Porque a fenomenologia nunca renunciou à sua fundação científica numa subjetividade transcendental, ela teria vindo mostrar e delinear por antecipação algumas tarefas da lógica analítica, a prática assertiva e o jogo das proposições enfraquecendo-se em exercícios de gosto através da busca inelutavelmente flutuante, indecisa e infinita de sua verossimilhança. Resta somente, para quem não compartilha dessa desqualificação da fenomenologia (em nome, vamos vê-lo, de uma lógica do evento incorporal), o investimento interno à fenomenologia, investimento que desemboca numa radicalidade da transcendência rente à questão da arte e de seu estatuto ontológico. É uma vertente da fenomenologia atualmente forte na França. Colocamos a questão: por que a fenomenologia encontra na fenomenologia da arte sua maior realização? Deleuze responde: para que

o vivido não torn(e) o conceito outra coisa senão uma opinião empírica enquanto tipo psico-sociológico (...é) preciso, portanto, que a imanência do vivido a um sujeito transcendental faça da opinião uma proto-opinião na constituição da qual entram a

16 DELEUZE; GUATTARI. Qu'est-ce que la philosophie?, p. 135-136.

17 Ibidem, p. 135.

18 Ibidem, p. 139. 
arte e a cultura, e que ela se exprima como um ato de transcendência do sujeito no vivido (comunicação). ${ }^{19}$

Porque a fenomenologia

precisa do belo e do bem para que (as opiniões originárias que nos ligam ao mundo como nossa terra) não se confundam com a opinião empírica variável e que a percepção e a afecção atinjam seu valor de verdade: se trata do belo na arte e da constituição da humanidade na história. ${ }^{20}$

A arte torna-se um instrumento fenomenológico para a constituição dos clichês, das Urdoxa... Uma vez invalidada, tratar-se-á de subtrair o controle fenomenológico do sensível para reecantá-lo dentro de um neo-materialismo. Tal é a virada. Eric Alliez resume-a assim:

da pura visão exigida por Husserl à vida livre de toda transcendência [...] É assim que a fenomenologia da arte como última etapa da fenomenologia da evidência é substituída por uma meta-estética material que vale por um novo começo da ontologia tornado possível pela im-possibilidade da fenomenologia, da qual se guarda a radicalidade do início - agora subtraída à influência do "positivismo fenomenológico" denunciado por Merleau-Ponty, como ao "credo parousifórico" da nova fenomenologia francesa. ${ }^{21}$

É preciso sempre voltar a Merleau-Ponty para entender quais são as sombras do filósofo-fenomenólogo. Carne, no vocabulário de Merleau-Ponty, corpo e matéria, para seus "descendentes". Para o último Merleau-Ponty, caberia à filosofia cavar a experiência do corpo, momento do mundo, os arcanos carnais da fé perceptiva à qual a pintura conduz de uma maneira mais segura do que qualquer filosofia. Dez anos depois, Lyotard convidará o pensamento do mestre para fundamentar sua proposta de uma desconstrução do impensado da arte ocidental enquanto figural sempre hipotecado pelo discurso que o trabalha de dentro. A grande tentativa de Lyotard consistirá em sugerir as vias para subtrair o sensível ao imperialismo, de origem hegeliana, da significação e para dar às imagens de arte, sobretudo pictóricas, uma autonomia e uma economia remetendo ao trabalho da figurabilidade e da des-figuração nos sonhos e no inconsciente, conceitos encontrados no paradigma cognitivo do freudismo. Phénoménologie de la perception; L'oeil et l'esprit; e Discours, figure podem constituir o material de análise do desempenho do sensível e de sua assinalação semiológica e expressiva nas artes, a fim de sustentar a tese de que a

19 Ibidem, p. 141-142.

20 Ibidem, p. 141.

21 ALLIEZ. Da impossibilidade da fenomenologia..., p. 97. 
fenomenologia da evidência está sempre-jà envolvida nas camadas do préteorético e do ante-predicativo. Não foi entre 1961 e 1971, isto é, em 1969, que Gilles Deleuze, numa seqüência da Logique du sens conceituava uma filosofia que fosse linguagem de corpo, uma filosofia que também fosse corpo? A virada de uma pura eidética para uma meta-estética material seria redobrada pela tarefa ética formulada por Michel Serres, outro monumento do pensamento francês surgido nos anos sessenta, a de rememorar, percorrer e reinventar através de uma hermenêutica de todos os fenômenos de perspectivação do Sentido nas produções simbólicas e epistemológicas — os caminhos levando à convicção de que "la morale c'est la physique": ${ }^{22}$ a física é a moral...

\section{A condição poética do pensamento}

Sem antecipar a análise do texto de Michel Serres, sua reinvindicação da rememoração do "poema da física" como ética do mundo poderia ser vinculada a uma das categorias condicionais da filosofia apontadas por Alain Badiou. No Manifeste pour la philosophie, breve livro que vem propor uma ultrapassagem das interpretações nihilistas francesas da filosofia "chegada a seu fim", Badiou formula quatro condições genéricas do pensamento filosófico, este caracterizando-se por sua competência em reunir numa configuração abrangente os eventos que elas realizaram. Essas condições genéricas são: o matema, o poema, o amor e a política. Para que a filosofia possa prolongar seu gesto, para conseguir um passo a mais no Ser, na Verdade e no Sujeito, Badiou — que propõe uma lógica "acontecimental/eventual" possibilitando a renovação desses três conceitos metafísicos - pensa que um evento deve ter marcado a situação dessas quatro áreas genéricas para que a filosofia possa juntá-las num só lugar. A filosofia dispõe e, portanto, cria um lugar "Um" das verdades novamente nomeadas. Mas a história da filosofia mostrou como uma dada constelação de pensamento (episteme) pode, em certos momentos e em certas condições, submeter o pensamento a uma das quatro condições genéricas e desequilibrar o bom balanceamento necessário a uma configuração válida. Badiou chama essa captura do pensamento por um de seus quatro campos condicionais uma sutura ("suture").

É "período" da filosofia uma seqüência de sua existência onde persiste um tipo de configuração especificado pela dominação de uma das quatro condições. Durante este período, os operadores de compossibilidade dependem dessa especificação. ${ }^{23}$

22 SERRES. La naissance de la physique dans le texte de Lucrèce, p. 162.

23 BADIOU. Manifeste pour la philosophie, p. 22. 
[...] Chamo de sutura esse tipo de situação. A filosofia está colocada em suspenso cada vez que suturada a uma de suas condições e, com efeito, interdita-se de edificar livremente um espaço sui generis onde as nomeações acontecimentais que indicam a novidade das quatro condições vêm inscrever-se e afirmar, num exercício de pensamento que não se confunde com nenhuma delas, sua simultaneidade, portanto, um certo estado configurável das verdades da época. ${ }^{24}$

$\mathrm{Na}$ sutura, a filosofia torna-se servidor empírico-transcendental da condição. Suturas positivista-científicas, sutura política, sutura poética, por exemplo, tornam a filosofia o instrumento de legitimação daquilo que lhe fornece o padrão de pensamento. A condição genérica está assim filosoficamente legitimada a "configurar praticamente o sistema geral do sentido." ${ }^{25}$ Badiou avalia que a delegação do pensamento a uma de suas condições genéricas leva a filosofia a efetuar-se "no elemento de sua própria supressão em prol daquele processo." ${ }^{26}$ É assim que se pode esboçar o entendimento do veredito do fim da filosofia: sua perturbação pela rede histórica das suturas. Uma das últimas é a sutura à condição poética: "a idade dos poetas", do romantismo até o recolhimento heideggeriano das poéticas de Hölderlin, Trakl, Rilke etc. Essa sutura não significa que a filosofia funciona como poema ou mimetiza a poeticidade (isso sendo, no entanto, um fenômeno a salientar), mas que a poesia está incumbida das funções da filosofia pela hermenêutica. Nos anos 1930, o escritor austríaco Hermann Broch defendia a idéia de que a obra literária devia resgatar as deficiências da filosofia após seu divórcio com a teologia. Broch pensava que, ao herdar as determinações metafísicas e cosmológicas que a filosofia perdeu, e sendo o que Deleuze chamará de "potência de universo"27, a obra de arte, através de uma forma de Aufhebung, teria mais faculdade e competência para revezar e prolongar o papel epistêmico e epistemológico da filosofia. A idade dos poetas é a idade do encontro e do cruzamento recíproco entre a poesia e a filosofia: "aquilo que deu potência ao pensamento de Heidegger, escreve Alain Badiou, foi o fato de cruzar a própria crítica filosófica da objetividade com sua destituição poética." ${ }^{28}$ Badiou lembra que Heidegger pensava também ter encontrado nessa poética destitutiva da objetividade o lugar invocatório de uma crítica da ciência. Hipótese: o materialismo estético e a ética da imanência da filosofia francesa recente teriam suprimido-conservado essa sutura à condição poética. Trata-se de um verdadeiro nietzscheanismo do

\footnotetext{
24 Ibidem, p. 42.

25 Ibidem, p. 43.

26 Ibidem, p. 41.

27 DELEUZE; GUATTARI. Qu'est-ce que la philosophie?, "affect, percept et concept".

28 BADIOU, Alain. Manifeste pour la philosophie, op. cit., p.54
} 
devir-artista da filosofia, cujo profeta, dentro da sequiência pós-estruturalista, chama-se Gilles Deleuze.

\title{
Ser e pensar, o mesmo ${ }^{29}$. A volta da imanência
}

Mesmo o "matema" (Badiou) parece fornecer o sítio de uma partilha com o "poema”. Eric Alliez o lembra a propósito de Les enjeux du mobile, livro de Gilles Châtelet. Numa determinação do físico-matemático como "conexão infrangível do corpo próprio, do virtual e do visível"30 , Châtelet está à escuta, dentro das ciências exatas, das relações entre pensamento e virtualidades préformais. Alliez precisa que o vitalismo pensante inerente às experiências diagramáticas apontado por Châtelet reata com uma forma de Naturphilosophie e não deixa de apreender o ser num gesto e numa plasticidade ideal-materialista. As formalizações das virtualidades físicas tornam

manifesto que um diagrama é para ele mesmo sua própria experiência. Os gestos que ele capta e sobretudo aqueles que ele suscita não são mais dirigidos para as coisas, mas participam de uma linhagem de diagramas, de um devir técnico. [Assim] a experiência de pensamento radical é uma experiência de permuta dos lugares da natureza e do entendimento. ${ }^{31}$

Não podemos esconder o que essa formulação tem de proximidade com certos aspectos do gesto filosófico inicial de Michel Serres. Na "introdução" a Hermes I. La communication (1969), Serres buscava substituir o modelo dialético pelo diagramático, indo da linearidade à "tabularidade", ressaltando que

\begin{abstract}
o necessitarismo rígido de uma mediação única é substituído pela seleção de uma mediação dentre outras. Isto representa uma vantagem notória, isto é, uma aproximação mais fina das situações reais, cuja complexidade deve-se em boa parte ao grande número das mediações praticáveis; e essa vantagem é devida à superioridade de um modelo tabular sobre um modelo linear, ou ainda ao fato de que um raciocínio a várias entradas e a conexões múltiplas é mais rico e flexível do que um encadeamento linear de razões, qualquer que seja o motor desse encadeamento, dedução, determinação, oposição etc. ${ }^{32}$
\end{abstract}

Das matemáticas aos mitos, como acrescentará Serres mais longe, situase algo da permuta dos lugares da natureza e do entendimento que Châtelet

29 NANCY. Corpus, p. 98-99; DELEUZE; GUATTARI. Qu'est-ce que la philosophie?, p. 41.

30 DESANTI. "prefácio" a CHÂTELET. Les enjeux du mobile, Mathématique, physique, philosophie. Citado em: ALLIEZ. Da impossibilidade da fenomenologia..., p. 68.

31 ALLIEZ. Da impossibilidade da fenomenologia..., p. 69.

32 SERRES, Michel. Hermes I. La communication, p. 13. 
apontava como linhagem de diagramas. Por plasticidade, propomos uma imagem-conceito que permita recolher as determinações tanto "eventuais" ("évènementielles") quanto materialistas escolhidas. É claro que para produzir um logos do mundo, projeta-se imagens de pensamento que encontram na "vida do mundo", como escreve Badiou, seu espaço de possibilidade, sua condição nova sempre reativada. Desembocam numa reencenação do sentido do mundo e do pensamento num materialismo plástico e hiper-móvel, porém verdadeiramente diagramatizado e cartografado através de uma máquina agenciadora que testemunha um desejo de criar linhas de fuga conceituais capazes de reinventar as figuras e realia neo-cosmológicas do mundo. É fundamental entender nessa perspectiva a presença das análises sobre a arte ou o fenômeno estético e plástico na sua genericidade, nos seus aspectos intersticiais, simbólicos e epistêmicos. Quando Deleuze e Guattari encontram na arte uma "aptidão de universo", eles se aproximam do desenho dos lineamentos de uma nova (a)cosmologia. Procedamos por passos. Pretender levar a filosofia ao nível de uma (a)cosmologia - entenderemos daqui a pouco a presença desse limiar (a)real... - obriga a uma aproximação sutil. Para isso, várias vias devem ser investigadas: depois da "metáfora" derridiana, componente-chave da linguagem filosófica, analisaremos o "devir-mundo" tanto em Deleuze quanto em Michel Serres e, enfim, o "toque", conforme Jean-Luc Nancy. Isso nos levará ao conceito de "evento incorporal", que é a mais fundamental reconquista de um filosofema antigo na filosofia francesa dos últimos quarenta anos.

\section{Criar o conceito, salvaguardar o infinito}

Deleuze e Guattari têm concebido uma verdadeira vida material do conceito. A filosofia é a vida do conceito, receptáculo e filtro geológico das migrações epistêmicas que o afet(ar)am. A vida dos conceitos é uma geografia cujas "razões" são de irrigação renovadora das velhas camadas sedimentadas dos conceitos sobre planos de imanência percorridos por deslocamentos rizomáticos. O plano de imanência não é o conceito, é o solo do conceito.

Os conceitos são agenciamentos concretos como configurações de uma máquina, mas o plano é a máquina abstrata cujos agenciamentos são as peças. ${ }^{33}$

Assim, a migração dos conceitos é uma das vias para sair da transcendência e investir uma nova territorialização do pensamento sobre a horizontalidade 
rítmica do mundo. O plano de imanência é capaz de escapar à vetorialidade fatal da metafísica. Assim, se Michel Serres lembra que a dialética significa um exercício truculento da linearidade, a determinação única e a univocidade da mediação, Deleuze e Guattari dizem que um impensado da metafísica levou sempre ao perigo de tornar os conceitos tantos universais que têm uma função de definição como de contemplação (a eidética), de reflexão (a crítica) e de comunicação (a fenomenologia). A conceituação do plano implica o evitamento das pretensões de tornar a filosofia uma pura ciência do ser, que projeta conceitos finais: os universais. Não se trata mais de tomar o mundo como objeto, de posicionar nele os objetos, as representações, os estados de coisas e as referências. Isso permite enxergar a vida do conceito como síntese disjuntiva que se diferencia muito do tradicional princípio metafísico de identidade que exclui da definição de uma coisa os predicados que não correspondem à sua identidade. Como a Lógica do sentido afirma, a síntese disjuntiva significa que "a exclusão dos predicados é substituída pela comunicação dos eventos." 34 Trata-se mais, com efeito, do mundo se desterritorializar numa nova imagem de pensamento. Os componentes do conceito têm vocação a criá-la, dando forma às correntezas aluviais e rizomáticas do plano de imanência.

Se a imagem clássica do pensamento era vontade de verdade, aquela sonhada e criada por Deleuze e Guattari é vontade de criação, uma motivação nietzscheana que Deleuze articula à visão spinozista da vontade como alegria da criação. Na vontade metafísica de verdade, a imanência está relacionada "com" ou "a". E atribuir a imanência "a" ("rapporter l'immanence 'à") significa submeter os conceitos aos universais e fundamentar as ilusões da filosofia. Deleuze acrescenta:

Um conceito é uma heterogênese, isto é, uma ordenação de seus componentes por zonas de vizinhança. Ele é ordinal, é uma intensão presente a todos os traços que o compõem. Não deixando de percorrê-los segundo uma ordem sem distância, o conceito está em situação de sobrevôo em relação a seus componentes. Ele é imediatamente co-presente sem nenhuma distância a todos os seus componentes ou variações, ele passa e repassa por eles: é um ritornelo, um opus com sua própria cifra. ${ }^{35}$

Como se pode ler na Logique du sens, o mundo-sentido sobrevoa as dimensões conforme as quais se ordenará... ${ }^{36} \mathrm{O}$ conceito de "incorporal" anuncia-se aqui. Não discursivo, não proposicional, não comunicacional, o

34 DELEUZE; GUATTARI. Logique du sens. col. 10/18, (24a série. De la communication des événements), p. 238-239.

35 DELEUZE; GUATTARI. Qu'est-ce que la philosophie?, p. 26.

36 DELEUZE; GUATTARI. Logique du sens..., p. 142. (15a série. Des singularités). 
conceito é multiplicidade e devir. A vida do plano de imanência é potência de um Um-Todo, um deserto movente e movediço que os conceitos lot(e)am. É nele que se cria uma imagem do pensamento.

Uma dobra ordena uma ida e volta perpétua entre o pensamento e o ser. Se pensar e ser são uma só coisa, é porque "o movimento não é imagem do pensamento sem ser ao mesmo tempo matéria do ser." ${ }^{37}$ Essa sentença é uma sentença fundadora de uma audição filosófica que reata com aspectos propriamente pré-socráticos. Nesse sentido, esse filosofar quer ser um pensar préfilosófico. O pré-filosófico torna-se condição da eficácia dos conceitos. Como? O plano de imanência "implica uma espécie de experimentação às apalpadelas, e seu traçado recorre a meios pouco confessáveis, pouco racionais e razoáveis." ${ }^{38}$ Enquanto corte do caos, o plano de imanência precisa do conceito para canalizar as velocidades infinitas e rapidíssimas que o atravessam. No plano, o conceito cria a condição para que elas contribuam para dotar de consistência seus próprios movimentos: "sem perder nada do infinito [...] cabe aos conceitos traçar as ordenadas intensivas desses movimentos infinitos." ${ }^{39}$ De fato,

a imagem de pensamento não retém nada senão aquilo que o pensamento pode reivindicar por direito [...] é o movimento infinito ou o movimento do infinito. ${ }^{40}$

Não foi por acaso que Deleuze e Guattari inventaram o pensamento enquanto diagrama. Deram à filosofia a tarefa de criar uma nova e paradoxal mathesis universalis, desembaraçada dos universais e da razão: a vontade neonietzscheana de criação desemboca na nova tríade filosófica: traçar(1), inventar(2), criar(3), quer dizer: os domínios do diagrama(1), das personagens conceituais(2) e das intensões(3). No traço diagramático do plano, na invenção das personagens conceituais e na criação dos conceitos, na co-adaptação das três instâncias, a faculdade do "gosto" está em jogo.$^{41}$ Filosofar exige alguma forma de gosto, para investir o plano pré-conceitual e saber enxergar nele as vias de doação de uma consistência que crie o crivo do evento. $\mathrm{Na}$ desterritorialização absoluta realizada na nova imagem de pensamento, na passagem da terra ou do cosmo pelo plano de um pensamento-ser, de um pensamento-natureza percorrido de movimentos diagramáticos infinitos,

37 DELEUZE; GUATTARI. Qu'est-ce que la philosophie?, p. 41.

38 Ibidem, p. 44.

39 Ibidem, p. 45.

40 Ibidem, p. 40.

41 Ibidem,. p. 74 
trata-se da possibilidade de uma nova ética: a possibilidade de crer no mundo. A ética não leva a uma origem, mas a um devir do mundo cujo desabrochar inventa-o a cada momento. Conforme uma tradição neo-nietzscheana francesa que caracteriza a filosofia e o pensamento desde Bataille até Deleuze, o devirartista da filosofia - a sutura poética como condição da reconquista de uma (a)cosmologia - desemboca num novo logos que chamaremos de geo-ético.

\section{O clinâmen: a moral é a física}

Para nossa época, Mille Plateaux é seu tratado e sua epopéia filosófica. Alain Badiou tem razão de enxergar na filosofia deleuze-guattariana uma forma de filosofia da natureza. Naturphilosophie? A filosofia francesa contemporânea, através de suas novas imagens de pensamento, abre caminho à questão de um logos do mundo. Três anos antes de Mille Plateaux, Michel Serres publicou La naissance de la physique dans le texte de Lucrèce (O nascimento da física no texto de Lucrécio). O conceito de clinâmen encontra uma reelaboração fascinante dentro da proposta de uma epistemologia, de uma filosofia e de uma ética baseadas na mecânica dos fluidos. Desde a colocação de sua filosofia sob o signo de Hermes, deus das encruzilhadas — um nome para mitologizar a complexidade dos processos de comunicação — , a filosofia de Michel Serres faz entrar o muthos, o logos, as produções simbólicas e epistemológicas numa isomorfia crítica e hermenêutica extraordinariamente original.

$\mathrm{O}$ conceito de clinâmen jà foi resgatado e reprojetado por Gilles Deleuze num anexo da Lógica do sentido (notadamente para sublinhar que o pensamento é tão veloz como o quantum minimum de tempo), mas Michel Serres dá-lhe uma força nova ao operar escolhas mitológico-transcendentais suscetíveis de subtrair o pensamento à hegemonia da mecânica mais vinculada à razão ocidental, a dos sólidos. Essa mecânica sempre foi privilegiada pela ciência e, acrescenta Serres, é isomórfica à violência antropológica que caracteriza a história. Serres analisa como o pensamento ocidental foi originado na "condição marcial", determinando assim um "mapa-múndi do saber" 42 guerreiro e violento, a história sendo um sintoma da natureza. A mecânica dos fluidos, pelo contrário, propicia uma ética venusiana dos fluxos capaz, a partir de declinações e inflexões sutis, de reorientar uma visão e um novo exercício ético do mundo: manso, mais produtivo e à altura dos desafios da entropia. Em uma palavra, funda uma prática renovada de rerum natura. O clinâmen é a menor inclinação possível abrindo o caminho à existência. 
O turbilhão é, portanto, a pré-ordem das coisas [...] O relâmpago declina, o clinâmen fulgura sobre a toalha de água [...] Esses fenômenos reconhecidos nas entranhas do sujeito não são diferentes daqueles que constituem o mundo [...] As coisas [...] buscam o equilíbrio logo após um desvio ("écart") determinante ou decisivo.

O clinâmen é:

o caminho otimizado da constituição. Traço aberto [...] em direção à existência conjuntiva. ${ }^{43}$

A lei de fogo e de incêndio do mundo histórico funda, portanto, uma moral de busca da ataraxia. O sábio (e não será a filosofia desse evento o caminho de uma sabedoria?) representa aquele (e aquilo, dentro da fenomenalidade do mundo) que

volta às turbulências iniciais, antes da desordem [...] O sábio é o mundo fundamental. Ele reencontra o ser material, aquele fundo do ser mesmo onde nenhuma ruga ainda perturbou a superfície das águas. ${ }^{44}$

Notemos que o plano de imanência de Deleuze e Guattari representa o domínio dessas águas; que a formação dos conceitos segue uma linha que encontra a do clinâmen: as variáveis e as variações sobre o plano pertencem a essa área da declinação material-ética. A palavra de ordem da filosofia é a palavra do mundo povoando o deserto da imanência.

Assim o sábio volta aos pactos da natureza [...] aos caminhos primordiais da matéria mesma. [...] Assim, a ataraxia é um estado físico, o estado fundamental da matéria; sobre esse fundo, os mundos se formam. [...] A moral é a física.[...] A alma do sábio está estendida ao universo global. O sábio é o universo. Ele é, pacificado, o pacto mesmo. ${ }^{45}$

Se na Natureza tudo é físico, é moral toda expressão que não é simbolização final mas, no sentido spinozista, explicação causal, tal como vimos Deleuze resgatar-lhe o sentido. O sábio - o filósofo - é o entendimento do mundo mesmo, o morador do sentido. Eis-aí porque chamamos essa prática do sentido uma geo-ética. Não é por acaso que Deleuze e Guattari intitularam um capítulo de Mille Plateaux uma "geologia da moral". Era preciso substituir por uma "geologia", a genealogia da moral. A que serve a filosofia, questiona Gilles Deleuze? A elevar a imagem de um Homem livre, liberado da necessidade do 
mito e dos distúrbios da alma. Parece delinear a topologia dessa morada ética: nem as alturas, suspeitas, nem as profundezas, mas as superfícies. O plano superficial constitui bem a nova geografia das alturas e das profundezas. No resgate e na rememoração do topos da superfície estóica ou das lavouras de Hércules, agrimensor e pacificador da terra, trata-se de um novo traço entre as coisas e as proposições. Na filosofia de Jean-Luc Nancy, os conceitos de "arealidade" e de "ex-crição" apresentam-lhe uma forma de exposição especulativa recente e ainda pouco conhecida.

\section{A arealidade concreta. Ser-ao-mundo}

\section{É preciso nunca deixar de apertar a fala, a língua e o discurso [...] seguir-se-á um corpo-a-corpo com a língua $[. .$.$] a exposição de um corpo tocado, nomeado,$ excrito fora-de-sentido, hoc enim. ${ }^{46}$}

As vias para tornar-se-mundo são múltiplas. Elas desenham uma moradia na multiplicidade mesma. Essa questão acha na filosofia de Jean-Luc Nancy uma formulação notável. Desde o início dos anos setenta, esse filósofo — que recebeu uma homenagem filosófica de grande porte na pessoa de Jacques Derrida $^{47}$ — percorre vários momentos ou sistemas da filosofia moderna (Descartes, Kant, o romantismo alemão, Hegel, Nietszche, Heidegger, Bataille, Blanchot etc.) — ou, mais precisamente, a sistematicidade inerente à dialética ocidental — para cumprir a seguinte idéia: "não interessa filosofar senão para tentar acompanhar até seu limite (o) esgotamento do discurso" e forjar "aquilo que o filosófo morto ainda deve articular". Se La remarque spéculative ${ }^{48}$ analisava a plasticidade do conceito de Aufhebung, isto é, os métodos de exposição especulativa de um conceito não-descartável do sistema que ele trama e dinamiza, a questão do ponto cego e motor do discurso dialético levou Nancy, pouco depois, a investigar em Kant o papel estruturante e ao mesmo tempo inassinalável do Esquematismo dentro da Darstellung filosófica. Le discours de la syncope I. Logodaedalus lembrava o fato de que toda filosofia, no gesto de fundação da verdade, implica um "indecidível" que é:

Superposição exata da mancha cega e do centro da visão [...ou] a potência mesma do mesmo - o que, pelo discurso, furta o discurso a seu próprio Saber Absoluto. ${ }^{49}$

46 NANCY. Corpus, p. 54.

47 DERRIDA. Le toucher, Jean-Luc Nancy.

48 NANCY. La remarque spéculative.

49 NANCY. Le discours de la syncope I. Logodaedalus, p. 12. 
Nancy acrescentava que um outro ponto cego do (mesmo) dialético é a própria sustentação do discurso:

Aquilo que funda, aquilo que sustenta, não deveria ser, ele mesmo, insustentável? Essa necessidade é a de toda onto-lógica metafísica e, ao mesmo tempo, sua deterioração radical — ou, mais precisamente, a deterioração da raiz mesma.$^{50}$

Nesse sentido, toda síntese filosófica é síncope.

O discurso filosófico é articulado sobre ou por uma síncope. Segura-o um indecidível momento de síncope. [...] A filosofia sempre comportou essa função [...] sempre soube o que ela tem de insustentável: é por essa razão que ela o denega e pretende saber ou pensar. (Ibidem)

Essas precisões inevitavelmente escassas - que permitem, no entanto, medir também como o início da trajetória de Nancy origina-se obviamente em motivações e prolongamentos pós-derridianos: a filosofia como estratégia e encenação da exposição retórica dos conceitos - são necessárias para entender o gesto logodedálico de Nancy, o acompanhamento do discurso filosófico sobre a linha de seus confins, beirando o esgotamento mas obedecendo à injunção de ainda discorrer e trabalhar para inventar uma outra chance para a filosofia, rente ao (à même) exercício da exposição especulativa: tanto sua expressão (Ausdruck) quanto suas figuras e seu ethos. O título do livro que Derrida consagrou "ao imenso evento filosófico" do pensamento nancyano restitue perfeitamente como ele é, desde seus primórdios, uma tentativa de desvendamento crítico do toque "infra-mince" (infra-fino) do especulativo.

Para Derrida, a questão nancyana dominante e inaugural é a do "toque" (toucher). Envolve a conceituação do sentido do mundo enquanto enunciado do corpo ou sua ex-crição no mundo. O sentido do mundo é um "toque". Em Corpus - a obra-prima da "inarticulação pensamento-corpo" ${ }^{51}$ —, Nancy tentava criar a imagem de pensamento desse "toque", um verdadeiro indecidável decisivo. Essa (in)articulação, notemo-lo, parece recolher muitas das decisivas indecidabilidades sincópicas que constituem o desafio inerente à meta-estética e à geologia da moral que caracterizam a vertente da filosofia francesa que expomos aqui. Derrida, aquele sem o qual nada da indagação sobre o discurso filosófico como retórica expositiva teria sido possível, reconheceu, no entanto, no Nancy dos anos noventa, o autor de um lance particularmente significativo. A epígrafe citada anteriormente, que fala da necessidade de "um corpo-a-corpo 
com a língua [...] a exposição de um corpo tocado" é fiel à linha da luxação da filosofia proposta por Derrida nas Margens e à necessidade de sempre relançar o filosofar para dar-lhe suas chances nos confins de seu esgotamento. Nancy, enfim, relaciona sua conceituação do corpo, outro conceito tipicamente francês - lembramo-lo a propósito de Deleuze e de sua ambição de uma filosofia que fosse corpo - com o prefixo "ex", o da es-critura tornada ex-critura: o pulso do corpo do sentido acha sua $e x$-tensão na $e x$-crição.

Um corpo expulsa-se [...] O sentido absoluto do mundo dos corpos, sua mundaneidade e sua corporeidade mesmas: a excrição do sentido, o sentido excrito. ${ }^{52}$

Nancy vai fazer do $e x$ - o lugar de radicalização, de saturação horizontal das determinações dual-negativas da fenomenologia, enlouquecendo sobretudo, com grande domínio, algo que lembra o plano de imanência deleuze-guattariano. Assim, Nancy parece aproximar-se de maneira asimptótica do "kosmotheorético" que ambicionava para dar uma seqüência a Logodaedalus, na perspectiva de estudar como, no ponto cego de sua estruturação, o discurso filosófico acha como segurar-se rente à (à même) sua síncope e sua indecidibilidade. (Kosmotheoros nunca foi escrito, talvez porque era preciso esperar e conhecer a (a)realidade, conceito dos anos noventa cuja intencionalidade (a)cosmológica é evidente, mas que a des-transcendentalização e a consagração do imperativo meta-estético e ético da imanência levaram a desqualificar.)

O que é o sentido? O que é o mundo? Tal é o espaço questionante da ética da imanência. Procurar o sentido do mundo, num primeiro momento, é afastálo (do referencial) da transcendência ou da imanência "a" denunciada por Deleuze. O mundo não tem mais sentido, ele é o sentido. Mundo, ou o ser-a (être-à). O fato de desapossar o ser do haver é uma tarefa gigantesca à qual Nancy tenta medir sua própria escritura, o frayage (abertura de caminho) de sua retórica. "Autrement dire" é o dever da filosofia que proclama esse "dizer de outra maneira" ${ }^{33}$, por uma via material, o "autrement qu'être" (medimos aqui como as intitulações dos discursos pós-fenomenológicos e pós-ontológicos de Emmanuel Lévinas podem imperar.) A ética é linguagética. Materialidade:

"Toucher": não se trata de significação, mas do sentido do mundo como sua concretude mesma enquanto aquilo a que nossa existência toca e pelo qual ela está tocada, em todos os sentidos possíveis [...] trata-se de um trabalho [...] do pensamento - do

52 Ibidem, p. 94.

53 NANCY. Le sens du monde, p. 22. 
discurso e da escritura onde o pensamento se põe a [...] tocar o que não é para ele um "conteúdo", mas seu corpo: o espaço dessa extensão e dessa abertura no qual e como o qual ele se ex-creve, isto é, deixa-se transformar em concretude e em praxis do sentido..$^{54}$

O sentido é a ex-crição de um "a", o ser-a do ser enquanto tal. Ex-crever é o jogo do mundo enquanto sua arqui-espacialidade, porque o mundo é o transporte sem resto dele, nele mesmo.

O sentido é o tornar patente ou o corporalizar do mundo. O mundo é disposição e não mais fenômeno: isso significa que a transcendência fenomenológica está afastada porque costuma repousar sobre uma pontuação saliente, sobre a saliência dos conceitos (rede fenomenológica do surgimento, do brilho, da luz, da aparição, da evidência, da epifania). A materialidade imanente não se articula com o transcendente. A filosofia vive uma forma de seu fim com a desilusão de uma possível reconstituição da identidade do sentido e da verdade. É bem a tensão entre a verdade e o sentido que define a filosofia. O chamado fim é o fim das citações às significações. Mas esse fim não pode se prolongar num pragmatismo: a filosofia se tornaria gesticulação. A geologia da ética diz: "fim das fontes, começo do excesso seco do sentido." ${ }^{5}$ Fim das fontes (a fonte, ponto de vista, visão eidética). Excesso seco, um estoicismo? A filosofia torna-se mesmo um toque, indubitavelmente incorporal - o mesmo do cúmulo corpóreo. Nele, o pensamento empenha-se a tocar seu próprio corpo. Nova visão e uma proximidade com a ambição deleuziana de purgar o campo transcendental de todo tipo de semelhança. Com efeito, como lemos na Lógica do sentido, não existe na linguagem um dublê, uma sombra ou um modelo das proposições que exprimem o sentido, nem sequer dos estados de coisas que as proposições designam. ${ }^{56} \mathrm{O}$ sentido não preexiste como algo a ser simbolizado. Areal (Nancy), superficial como toque e encontro das alturas e das profundezas, o sentido, diz Deleuze, não reproduz, mas "insiste, subsiste ou persiste" na proposição como um incondicionado. Veremos daqui a pouco como isso recebe do conceito de evento sua trama conceitual, quando se tratará de apresentá-lo como identidade de uma forma e do vazio, e não mais, como na predicação tradicional, entre um objeto e seu designado. Morte do espelhamento (du "spéculaire"), daquela semelhança que leva a conceber toda condição à imagem do condicionado. Uma vez desaparecidas as visões do mundo, sobra a possibilidade de ver as linhas de fuga desenharem o sentido de uma

54 Ibidem, p. 22-23.

55 Ibidem, p. 44.

56 Ler DELEUZE. Logique du sens. (17a série. De la genèse statique logique) 
(a)cosmologia "que não seria mais tomada sob o olhar do kosmotheoros, daquele sujeito panóptico do saber do mundo"57

O nó nancyano com os gestos filosóficos tanto deleuze-guattariano quanto serresiano encontra-se na convicção de que uma filosofia da natureza ainda é possível, enquanto "filosofia dos confins." 58 Daí o encadeamento das articulações: o mundo é a totalidade dos existentes, ou pura multiplicidade infinita; o novo existencial da nossa época, existencial do ser-a, é a "fractalidade" de todos os fragmentos e de todas as hecceidades do mundo ("heccéités"). É muito importante entender em que medida o caráter patente do mundo exige a colocação a nu dos existentes enquanto fragmentos: a abertura enquanto tal é abertura do mundo ou "toque". Tem apenas corpos que se tocam, "fractalidade" total. No afastamento da transcendência, o ser- $a$ é ex-posto e ex-crito. Nancy reinveste o sentido deleuze-guattariano enquanto percurso e ex-pressão das superfícies. A alusão aos filósofos atomistas (referência de Michel Serres na abordagem da moral enquanto física) abre à

arqui-tese originária da filosofia [...], a saber, o espaçamento originário enquanto materialidade, e esse espaçamento como existencial [...] A matéria não é a espessura imanente absolutamente fechada em si, ela é primeiro, e ao contrário, a diferença pela qual alguma coisa é possível, enquanto coisa e enquanto alguma: isto é, de outra maneira que como inerência ou induração indistinta de um "um" que não seria algum um. ${ }^{59}$

Isso, Nancy o chama de "arealidade concreta." 60

A "circularidade da realidade e da materialidade [...] é a condição mesma de todo toque (toucher), de todo contato, isto é, de todo agenciamento de um mundo (nem continuidade, nem descontinuidade puras: toque) [...] a idealidade do sentido é indissociável de sua materialidade." ${ }^{1}$

Daí o privilégio reservado à ex-crição da/na arte. Duas vertentes se conjugam para sustentar sua força ética: [o sentido cumpre-se na existência e completase nela $(\mathbf{X})$ o sentido é co-extensivo aos confins do mundo] $+[$ o mundo extende-se até as extremidades do sentido, absolutamente]: a arte é o conjunto infinito, a multiplicidade das aberturas de caminhos ("frayages") da singularidade de existir. ("le frayage multiple de la singularité d'exister"). ${ }^{62}$

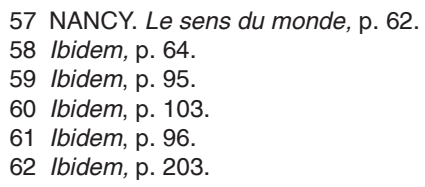


A lógica do evento ecoa nos fundamentos da filosofia do sentido de Nancy: o vocabulário o faz sentir com força. «A singularidade é material.» Ela é «événement»ou

unicidade de existência. [...] Assim, o traçado dessa assinatura está sempre um corpo, uma res extensa enquanto extensão — arealidade, tensão, exposição — de sua singularidade. Corpo exposto: não é a ordenação em visibilidide daquilo que teria sido oculto, fechado. Aqui, a exposição é o ser mesmo, e isso se formula: o existir. Expeausition (ex-pele-ção): assinatura à pele mesmo, como a pele do ser. A existência é sua própria tatuagem. ${ }^{63}$

Além da saliência que levou Nancy a inscrever o discurso filosófico na área das estratégias plásticas e retóricas (Derrida diria fictícias) de exposição do sentido, algo, na incisão da "peau" (pele) parece levar à contemplação de vários aspectos fascinantes: a filosofia como sentido; o sentido como corpo; o corpo como toque; o toque como ex-peau-sição. Toda a fenomenologia da aparição está à beira do retorno, mas, rente a seu surgimento, ela atesta menos qu'il y a (de) l'être do que ex-tende a evidência de que há apenas exposição do sentido, sem reenvio a verdades condicionantes. Eis-aí algo do núcleo cego, in-situável, areal e (a)cósmico da indecidibilidade mesma. Trata-se da produção de uma visão meta-estética da arealidade através, no final das contas, de uma Kosmotheoria paradoxal, porque desprovida de sobrevôo, mas totalmente paralela e presa à horizontalidade dos deslocamentos rizomáticos sobre o plano de imanência. Nisso, a arte tem um papel fundamental, porque ela é sobretudo o sintoma ontológico do mundo, traçado e toque local da arealidade, sempre fragmentado, porque o fragmento rege a exposição e a ex-crição do mundo. Aqui, Nancy rememora algo do "fragmento absoluto" dos românticos de Iena e da Athenaeum, totalidade fragmentária progressiva, porque em ato e ex-pondose como toque do sentido. É o toque do evento. A arte é o espaço privilegiado de captação das velocidades, dos fluxos, do clinâmen do mundo. A arealidade combina, numa motivação e numa figuração deitada — meta-geológica — as linhas de vertente da física lucreciana, resgatada por Serres, e as constelações rizomáticas e imanentes de Deleuze. A arte ${ }^{64}$ é aquele plano do devir (Deleuze) que ordena a vinda (Nancy). E ordenar a vinda tem ainda muito a ver com o

63 Ibidem, p. 98. Em francês, a palavra "ex-peau-sition" se pronuncia como "exposition" (exposição). O "peau" de ex-peau-sition vem substituir o "po" de exposição e significa que uma exposição é também exposição da "pele" (da "peau") do sentido.

64 Não é por acaso que os livros de Jacques Derrida são um questionamento da linguagem e da voz metafísicas, que os tratados de Deleuze e Guattari investigam a produção literária e artística, medindo o plano do conceito com o plano de composição da arte, e que Michel Serres fez também deles o fundamento de uma legenda filosófica fabulosa. 
kosmeo grego: arranjar, ordenar e adornar para, através de uma segunda pele - o traje feminino e seus panejamentos - proporcionar-se com o cosmo e levar à manifestação uma certa configuração do mundo. Graças à arte, viemos a ser (com o) mundo. Na verdade, esse vir a ser — talvez a andadura e o girar de pena da exposição do sentido, porque estamos aqui dentro de dimensões como o ritmo, as pulsações e uma ordem que fazem aparecer (o haver-kosmos da Korè grega que "kosmea"...) — , também realiza um evento cuja indecidabilidade diz respeito a seus confins e a seus cúmulos: ser corpo ou incorporal, o grande feito dos corpos levados à incandescência de sua ex-peausição sendo o evento incorporal de seu devir. E moral é o recolhimento do evento incorporal e areal do mundo. A Expressão é-lhe indissociável. Ela é tramada nos eventos que fundam a linguagem porque a esperam tanto quanto esperam por nós. A linguagem dá-lhes como existirem puramente. ${ }^{65}$ Bem diferente, portanto, é a designação, que redobra e reflete uma referência e a Expressão que, como Deleuze o reparava na sua notável análise de $O$ problema da expressão em Spinoza (1968), é Explicação e Envolvimento ("enveloppement"), o Explicar sendo o desenvolvimento da coisa em si a partir de si, e o Envolver, uma implicação. ${ }^{66}$ Ambos colocam antes toda demonstração no absoluto.

\section{A lógica do evento. $O$ devir-mundo}

A filosofia francesa recente, enquanto plano de criação, é uma filosofia do evento. O evento é o infinito ao qual é preciso dar consistência e que é necessário frear e canalizar para não o perder e cujas velocidades acontecimentais podem levar a existência à sua altura.

O evento é imaterial, incorporal, invivível: a pura reserva [...] a virtualidade tornada consistente. É o que chamamos de evento, ou a parte daquilo que escapa à sua própria atualização em tudo o que ocorre. O evento não é o estado de coisas, ele se atualiza num estado de coisas, num corpo, num vivido, mas ele tem uma parte de sombra e segredo que não cessa de subtrair-se ou de acrescentar-se à sua atualização: ao contrário do estado de coisas, ele nem começa nem acaba, mas ele ganhou ou guardou o movimento infinito ao qual ele dá consistência. Ele é o virtual que se distingue do atual, mas um virtual que não é mais caótico, tornado consistente ou real sobre o plano de imanência. Real sem ser atual, ideal sem ser abstrato. ${ }^{67}$

65 DELEUZE. Logique du sens., p. 227. (23a série. De l'Aiôn)

66 DELEUZE. Spinoza et le problème de l'expression, p. 12.

67 DELEUZE; GUATTARI. Qu'est-ce que la philosophie?, p. 147-148. 
Nesse sentido, ele é incorporal. A análise extensa desse conceito por Émile Bréhier em La théorie des incorporels dans l'ancien stö̈cisme inspirou Deleuze, que lhe deu força em Lógica do sentido. O evento transforma incorporalmente os corpos e os estados de coisas. A transformação incorporal lhe é atribuída. O conceito de heccéité (hecceidade) lhe é também indissociável. Pertence à lógica do evento, uma lógica nem subjetiva, nem objetiva. Os parâmetros para o evento e a hecceidade são os mesmos: "não tem nem começo nem fim, nem origem nem destinação; está sempre no meio." ${ }^{68}$ A semiótica que a exprime pertence ao tempo não pulsado do evento ou devir. Hecceidade: é uma estação, um inverno, uma hora, que tem uma individualidade atuante, tocando os corpos, mas sendo apenas, enquanto incorporais, o expresso dos enunciados.

Blanchot tem razão de dizer que o A GENTE e o ELE - a gente morre, ele é infeliz — [...] destituem todo sujeito em prol de um agenciamento de tipo hecceidade [...] O ELE não representa um sujeito, mas diagramatiza um agenciamento. ${ }^{69}$

"Ele", "se", "a gente" são os indefinidos da multiplicidade. Mas é preciso dar uma linha de expressão ao evento incorporal, enunciá-lo, porque somente enquanto expresso dos enunciados o evento incorporal pode ter sentido. A fundamentação da filosofia "eventual" acha no incorporal como expresso dos enunciados seu evento privilegiado. No dizer: "ele envelhece, ele enrubesce, ele cresce", as enunciações não têm corpo, são incorporais, mas afetam os corpos. $\mathrm{O}$ atributo do corpo é o expresso incorporal dos enunciados. A linguagem torna-se a linha privilegiada dessa expressão (é tão desterritorializada que permite a repetição da enunciação). Medimos até que ponto o evento enquanto incorporal é próximo da arealidade nancyana. Tudo é pelo que ocorre, mas sem dizer como Wittgenstein: o mundo é o conjunto dos fatos ocorrendo. A meta-estética e a ética indissociáveis nas filosofias que nos interessam aqui levam à filosofia do perpétuo ocorrer, do perpétuo evento que o mundo é - a arealidade integral de sua ex-peau-sição - dentro de uma geologia da moral onde a sentença de Serres brilha como lema: a moral é a física.

O gesto filosófico deleuze-guattariano está colocado em abismo na sequiência de Mille Plateaux na qual a conquista pela linguagem da autonomia de sua linha de expressão sobre o estrato orgânico está formulada. Se é preciso dar expressão ao incorporal, talvez seja também porque os estados de coisas são atravessados por ele. A filosofia deve recolher o evento, para prolongar-se 
numa transformação criativa do mundo. Por essa razão, a geologia da moral desemboca na "alloplástica" ou capacidade instrumental de agir sobre o mundo exterior. O corpo-a-corpo da escritura filosófica do mundo é um evento cuja ressonância é o incorporal de um efeito capaz de mudar o mundo e a moral geologicamente. Tal é o alvo do espaçamento da imanência. Organon acósmico, essa filosofia não pode deixar de se abrir no limiar desterritorializado do signo, para levá-lo no jogo geo-lógico do devir generalizado. A linguagem é um de seus eixos: "todos os movimentos, mesmo os mais violentos, precisam de traduções." "70 Quando, ao ler de Rerum natura, Michel Serres proclama que a única dialética é a da circunstância - stances, constances, instances, "todas as coisas da natureza [...] são instáveis [...] não pode ter uma última instância, tem apenas instâncias, e por todas partes, sobre os ciclos, e alhures"71 —, ele exprime perfeitamente uma lógica do sentido, enquanto fluxo, fluxo como hecceidade, onde se conjugam o ritmo do mundo e o ritmo da Expressão. Não seriam as stances, constances, instances as palavras serresianas para "l'insistance, la subsistance ou la persistance" deleuzianas do sentido $?^{72}$ Essa filosofia traduz o gesto do mundo, ou, como escreve Badiou, ele é

uma descrição em pensamento da vida do Mundo, tal como esta vida, assim descrita, possa incluir como um de seus gestos vivos, a própria descrição. ${ }^{73}$

Trata-se de uma sabedoria, como dizem Deleuze e Guattari, 'Être à l'heure du monde. Estar à hora do mundo"74, isto é, na cir-cun-stância. Passar por todos os componentes, para que a filosofia possa diagnosticar nossos deviratuais. A conceituação da arealidade (Nancy), da moral enquanto física (Serres), da singularidade, do devir-outro e do evento significa uma sabedoria sem transcendência. Para criar uma filosofia do acontecimento não remetendo ao estado das coisas ou às referências e correlações do fenômeno, era preciso desembaraçar o exercício da razão da exigência da correlação noéticonoemática, da exigência da definição da objetividade do conhecimento, da exigênca de uma subjetividade sempre demasiado cartesiana, da exigência da vontade de verdade enquanto citação à significação. Para realizar a vocação da filosofia que nunca renunciou à conquista da sabedoria; era preciso sair da racionalidade pós-clássica, operar uma de-construção dos filosofemas da

\footnotetext{
70 Ibidem, p. 82.

71 SERRES, Michel. La naissance de la physique dans le texte de Lucrèce, p. 78.

72 Cf. Nota 56.

73 BADIOU, citado em: ALLIEZ. Da impossibilidade..., p. 95.

74 DELEUZE; GUATTARI. Mille Plateaux, p. 343.
} 
metafísica, uma Erinnerung dos filósofos da imanência (Spinoza), um devirartista (Nietzsche); era preciso realizar um verdadeiro revertimento das prioridades do pensamento em nome de uma nova imagem de pensamento, em nome de um agenciamento de novos conceitos, de uma geo-ética e de um materialismo do ser-(ao-)mundo. O devir-intenso, o devir-animal, o devirimperceptível, devires tão provocativos, são as palavras de ordem da moral: devenir tout le monde. Tornar-se todo o mundo, isto é, o contrário da semelhança de massa.

A meta-estética francesa do pensamento é uma ética do sentido que cria as linhas de fuga, as vertentes e as declinações de uma liberdade que nos exige, conforme Deleuze, percorrer todas as individualidades, para extrair-lhes um evento único do qual nascerá o indivíduo. ${ }^{75} \mathrm{~A}$ nova chance da filosofia ambicionada por Nancy demonstra a pertinência de uma forma de reatamento da filosofia com um gesto finalmente pré-socrático: fazer seu próprio poema. Projetar uma mathesis cuja Expressão é uma ontologia do conceito que requer o toque do incorporal dentro de sua eventualidade. Essa configuração da Expressão é mesmo necessária a todo devir-ético como poder e potência de alegria.

\section{Referências}

ALLIEZ, Eric. Da impossibilidade da fenomenologia. Sobre a filosofia francesa contemporânea. São Paulo: Editora 34, 1996.

BADIOU Alain. Manifeste pour la philosophie. Paris: Seuil, 1989.

DAMISCH, Hubert. L'origine de la perspective. Paris: Flammarion, 1987. (Col. Champs)

DELEUZE, Gilles. Spinoza et le problème de l'expression, Paris: Minuit, 1968. (Col. "Arguments") Logique du sens. Paris: Minuit, 1969

DELEUZE, Gilles; GUATTARI, Félix. Mille Plateaux. Capitalisme et schizophrénie. Paris: Minuit, 1980. . Qu'est-ce que la philosophie? Paris: Minuit, 1991.

DERRIDA, Jacques. L'écriture et la différence. Paris: Seuil, 1967. . Marges de la philosophie. Paris: Minuit, 1972. Le toucher, Jean-Luc Nancy. Paris: Galilée, 2000.

DESANTI, J. T. "Prefácio" a CHÂTELET, Gilles. Les enjeux du mobile, Mathématique, physique, philosophie. Paris: Seuil, 1993.

HABERMAS, Jürgen. Le discours philosophique de la modernité. Paris: Gallimard, $n r f, 1988$.

75 DELEUZE. Logique du sens. (25a série. De l'univocité) 
LACOUE-LABARTHE, Philippe. Typographie. In: Mimesis des-articulations. Paris: Aubier/Flammarion, 1975.

LYOTARD, Jean-François. Discours, figure. Paris: Klincksieck, 1971.

NANCY, Jean-Luc. Corpus. Paris: Métailié, 1992.

. Le sens du monde. Paris: Galilée, 1993.

. La remarque spéculative. Paris: Galilée, 1973.

. Le discours de la syncope I. Logodaedalus. Paris: Aubier-Flammarion,

1976. (Col. "La philosophie en effet")

SERRES Michel. Hermes I, La communication. Paris: Minuit, 1969. . Hermes I. La communication. Paris: Seuil, 1984. (Col. Points) . La naissance de la physique dans le texte de Lucrèce. Paris: Minuit, 1977. 